\title{
APPLICATION OF ImageJ SOFTWARE IN THE ASSESSMENT OF FLOWERING INTENSITY AND GROWTH VIGOR OF PEAR TREES
}

\author{
Short communication \\ Waldemar TREDER ${ }^{\circledR}$, Krzysztof KLAMKOWSKI*®D, Anna TRYNGIEL-GAĆ®D, \\ Katarzyna WÓJCIK \\ The National Institute of Horticultural Research \\ Konstytucji 3 Maja 1/3, 96-100 Skierniewice, Poland \\ Received: July 2021; Accepted: October 2021
}

\begin{abstract}
The study evaluated the possibility of using the image acquisition and processing method with ImageJ software for estimating growth vigor and flowering intensity of 'Conference' pear trees. For assessing flowering intensity, manual counting of flower clusters and taking of photographs of the trees were conducted at full bloom. Tree vigor was estimated by manually measuring the total length of the central leader and shoots of individual trees. The trees were photographed from the same distance using a hand-held camera. The calibration model for assessing the vigor or flowering of trees by image analysis was based on measurements and photographs taken for nine selected trees differing in the total length of shoots or in the number of flower clusters. Then, a quality assessment of the model was carried out on 26 nonselected trees. Image processing was performed using ImageJ software. High regression coefficients were obtained between the surface area of petals measured on the photographs and the number of inflorescences counted $\left(\mathrm{r}^{2}=0.98\right)$; however, observations carried out in the following year indicate the need for individual calibration of estimation models in each evaluation season. Subsequently, the quality of estimating the flowering intensity of pear trees was assessed using a previously determined calibration model. Mean absolute percentage error (MAPE) values ranged from $14.0 \%$ to $21.8 \%$, depending on the measurement time. In the assessment of tree growth vigor, a high correlation $\left(\mathrm{r}^{2}=0.98\right)$ was also obtained between the actual length of shoots measured individually for each tree and the values obtained by analyzing the photographic image, where the MAPE error was $12.9 \%$.
\end{abstract}

Key words: Pyrus communis, image analysis, plant morphology

\section{INTRODUCTION}

Yielding of fruit trees depends on many environmental and biological factors. The most important environmental factors are air temperature and humidity, insolation, and the availability of water and minerals. Biological factors include the general condition of the trees, their size, and flowering intensity. The yield potential of fruit trees is correlated with the volume of their crowns and the intensity of flowering (Treder 2010). The greater the volume of the tree crown, the greater the number and total length of shoots on which flower buds can set. Modern intensive fruit growing is characterized by the high yielding of trees already in the first years after planting. That is why fruit growers look for nursery trees with a strong leader and an extensive crown with many lateral shoots. The use of strong, well-branched nursery trees is a prerequisite for early and high yields (Theron et al. 2000). Since fruits develop from flowers, the yield-forming potential of trees, regardless of their size in a given year, depends primarily on the number of flower buds developed in the spring. The size of the tree, in 
turn, determines the number of fruits it can produce while maintaining the desired fruit quality. Consistent production of the fruit of optimum size can only be accomplished when a proper balance between vegetative growth and fruiting is maintained (Reginato 2002; Treder 2010). Frequently, pear trees bloom abundantly and set too many fruits to optimize the fruit size and return bloom. Fruit growers must continuously improve their orchard agricultural practices to meet consumer demand for better quality fruit (Dobbs \& Rowling 2006).

Flower and fruit thinning are considered some of the most important cultural practices affecting fruit quality and cropping consistency (Byers \& Carbaugh 2002). The knowledge of flowering is useful for the development and optimization of crop management practices. Methods to rapidly quantify flowers might also be of interest to breeders who select plants with specific flowering characteristics (Ohnishi et al. 2010, Thorp \& Dierig 2011).

The determination of the number of flowers has traditionally been performed manually, which is very laborious and time-consuming. For that reason, attempts to use methods based on an image processing technique have been proposed and tested. Image analysis techniques have been used in a variety of new methods applied in crop production and agricultural research (Patil \& Bodhe 2011; Arjenaki et al. 2012; Treder et al. 2016). Researchers have begun to explore digital photography in various monitoring applications. RGB (red-blue-green) imagery has been shown to be an effective way to measure leaf surface area (O'Neal et al. 2002; Patil \& Bodhe 2011; Easlon \& Bloom 2014), to estimate vegetation coverage and plant biomass (Lukina et al 1999), or to detect pests or pathogens (Padmavathi \& Thangadurai 2016). It is worth mentioning that a similar approach has also been adopted for optimizing fertilization management by assessing nitrogen (chlorophyll) status in the leaves of some crop species (Treder et al. 2016). Attempts have also been made to use image processing for estimating the intensity of flowering of some crop species, including apple trees (Aggelopoulou et al. 2011; Hočevar et al. 2014). To date, no data are available on estimating the flowering intensity of pear trees using the image processing approach.
The growth vigor of trees, and thus their yield potential, is determined by measuring the circumference or diameter of the trunk, which is usually converted to the cross-sectional area of the trunk. This parameter, however, does not accurately describe the yield potential of trees because it does not take into account the fact that the ratio between the trunk diameter and the total length of shoots, and thus the volume of the crown, changes over the years. A reliable assessment of the growth vigor of fruit trees has practical application in scientific research, breeding work, and also as a tool in agrotechnical decision-making systems. Unfortunately, with the increase in the cost of human labor, the previously used manual measurement methods can now be of use to a very limited extent. The rapid development of imaging techniques has made it possible to use novel digital image acquisition tools and computational processing for the description of plant morphology. There are several commercial (e.g., WinRhizo, Imaris, Amira) and open-source platforms (e.g., Digimizer ImageJ19, CellProfiler20, Vaa3D21, BioImageXD, Icy22, KNIME23) for analyzing biological images (Schindelin et al. 2012; Spalding \& Miller 2013; Easlon \& Bloom 2014). Generally, manufacturers of image recording devices include dedicated image processing software, but these programs are usually of limited functionality (Abràmoff et al. 2004). A powerful, opensource platform for image processing, developed by Wayne Rasband at the National Institutes of Health (Bethesda, USA), is ImageJ (Schneider et al. 2012). The ImageJ software holds a unique position because it is easy to use, can perform a full set of imaging manipulations, and has a huge and knowledgeable user community (Rueden et al. 2017). The Image J method of image analysis is known to be accurate and has been used in studies assessing some morphological traits (mostly leaf-specific area) of crop plants (Gao et al. 2011; Juneau \& Tarasoff 2012). Limited data exist in the literature on the evaluation of fruit tree vigor and flowering intensity using the image acquisition and processing approach. The aim of the work presented here was to evaluate the possibility of using the ImageJ software to determine the growth vigor and flowering intensity of pear trees. 


\section{MATERIALS AND METHODS}

\section{Site description, plant material, and image ac- quisition}

The research was carried out in the Experimental Orchard of the National Institute of Horticultural Research in Skierniewice, Poland (latitude $51^{\circ} 57^{\prime} \mathrm{N}$, longitude $20^{\circ} 08^{\prime} \mathrm{E}$, altitude $120 \mathrm{~m}$ ). The study was performed on young 'Conference' pear (Pyrus communis L.) trees grafted on Quince C (Cydonia oblonga Mill.). The experimental trees were planted in 2013 at a spacing of $3.5 \mathrm{~m} \times 1.5 \mathrm{~m}$. The trees were trained as a spindle to a height of 2.5-3 m. Lateral branches were bent with strings and fastened to the trunk to reduce tree vigor and induce flower bud initiation. To keep the crown size within the allotted space, the trees were pruned annually in March (at the stage of swollen buds/bud burst). Only strongly growing shoots on the inside of the crown were removed.

For assessing flowering intensity, manual counting of flower clusters and taking of photographs of the trees were conducted at full bloom in 2015. In 2016, photographs were taken 3 days before full bloom and also during the full bloom of pear trees. The number of flower clusters on individual trees was manually counted on the day of image acquisition. The calibration model for assessing flowering intensity by image analysis was based on measurements and photographs taken for nine selected trees differing significantly in the number of flower clusters. Quality assessment of the model was carried out on 26 nonselected trees. For the assessment, the flowering trees were photographed against a black background, always from the same distance. In order to scale the size of objects in the photograph, a reference marker of known dimensions was placed on the background surface.

Tree growth vigor was estimated by manually measuring the total length of the central leader and shoots of individual trees. The calibration model for assessing the vigor of trees by image analysis was based on manual measurements and photographs taken for nine selected trees differing in the total length of shoots. Quality assessment of the model was carried out on 26 nonselected trees. Photographs of trees were taken after all the leaves had fallen off. Due to the large size of trees in 2016, the assessment of their size was carried out only in 2015.
For the assessment of total shoot length, trees were photographed from the same distance. In order to scale the size of objects in the photograph, a reference marker with known dimensions was placed near the tree. The photographic images were recorded with a Nikon CoolPix P520 digital camera equipped with a 4.3-180 mm objective lens.

\section{Analysis}

The image analysis procedures are schematically shown for the assessment of flowering intensity in Figure 1, and for tree growth in Figure 2. All image processing was performed offline using ImageJ software. Images were first loaded from the camera's memory card to a computer. Then, thanks to the marker placed on the background (for the photographs taken during flowering) or near the tree (photographs taken in the winter to assess the total length of tree shoots), the scale for a specific photograph was set.

\section{Estimation of the number of flower clusters}

In the next step, only the area where the flowers were visible was duplicated from the entire photograph. To estimate the number of flower clusters on the trees, it was decided to use the contrasting white color of pear perianth petals. Areas with the white color were separated using the command "Color Threshold" (Fig. 3). The total surface of the separated area was then measured (in $\mathrm{cm}^{2}$ ) by using the command "Measure".

After processing the photographs, a calibration regression model was built to relate flower surface area $\left(\mathrm{cm}^{2}\right)$ to the number of flower clusters. The calibration model determined in this way was used to assess the intensity of flowering of subsequent trees.

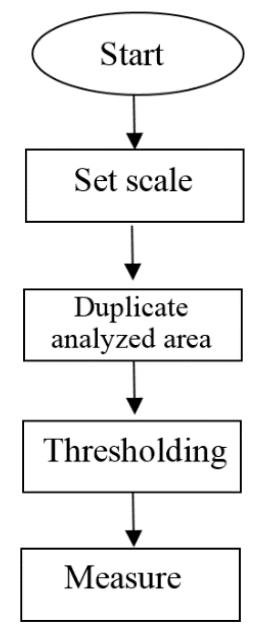

Figure 1. Flow chart of the image processing procedure for measuring the total surface area of flowers 


\section{Growth of tree shoots}

After setting the scale in the photograph, the image of the entire tree was copied. The next step was to eliminate the background by using "Subtract Background" and "Color Threshold" commands, and generate a tree skeleton using "Make Binary" and "Skeletonize Process" (Fig. 4). The total length of branches (in $\mathrm{cm}$ ) of the individual tree was measured by using "Measure_Skeleton_Length_Tool"plugins.

Finally, the manual and automated measurements were compared. Quality assessment of the developed models was carried out by determining the mean absolute error (MAE) and the mean absolute percentage error (MAPE) of estimation.

MAE is the average of all absolute errors.

$$
M A E=\frac{1}{n} \sum_{i=1}^{n}\left|y_{i}-x_{i}\right|
$$

MAPE is a statistical measure of how accurate a forecast system is.

$M A P E=\frac{100 \%}{n} \sum_{i=1}^{n}\left|y_{i}-x_{i}\right|$

$\mathrm{n}-$ the number of errors

$y_{i}$ - automated measurement (predicted value)

$x_{i}$ - manual measurement (true value)

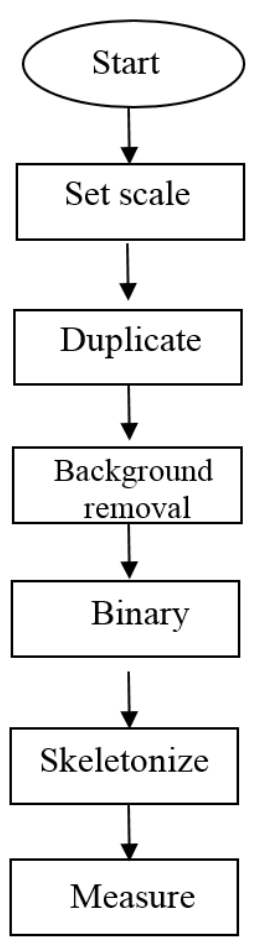

Figure 2. Flow chart of the image processing procedure for measuring the total length of tree shoots

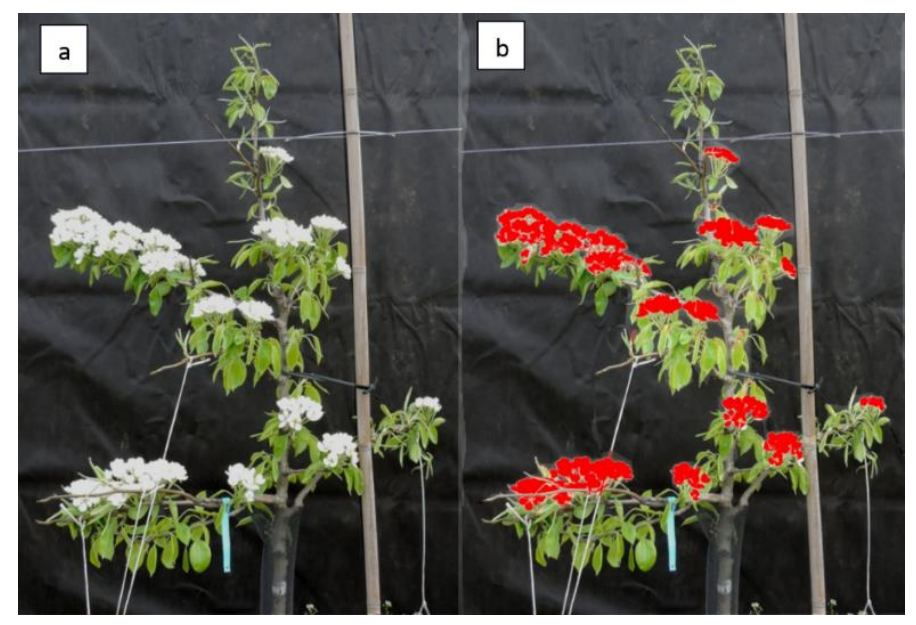

Figure 3. Example of image processing for the assessment of flowering intensity ( $a$ - original image, $b$-image after thresholding)

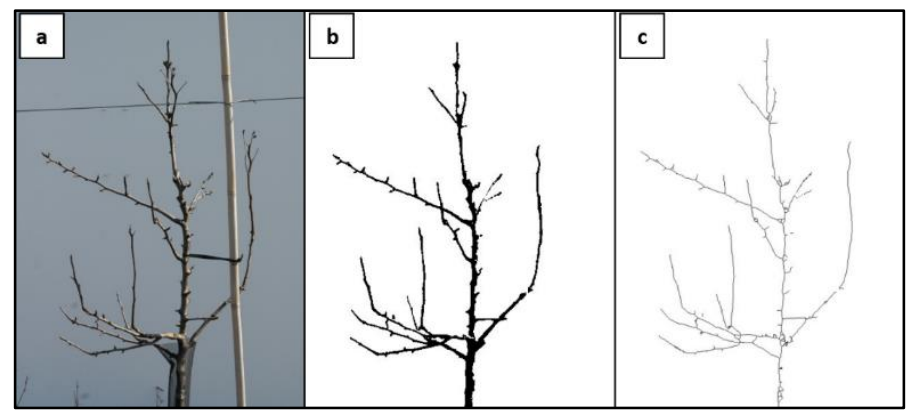

Figure 4. Processing steps for skeletonizing the photographic image of a tree ( $\mathrm{a}$ - original, $\mathrm{b}$ - binary, $\mathrm{c}-$ skeleton) 


\section{RESULTS AND DISCUSSION}

\section{Assessment of number of flowers}

Based on the description of the correlation between the total surface area of perianth petals (white color) determined by analyzing photographic images of pear trees and the actual (counted) number of inflorescences, a calibration model was developed in 2015 that was used for estimating the flowering intensity of pear trees (Fig. 5). This calibration model was described by a second-degree polynomial at a $98 \%$ level of determination.

In the next step, the quality of estimating the flowering intensity of pear trees was assessed using the previously determined calibration model. Analysis of the results obtained showed that the estimates were strongly correlated (determination coefficient of $83 \%$ ) with those determined by image analysis (Fig. 6).

Preliminary analyses in 2016 (unpublished data) showed that the use of the calibration model developed in the previous season for assessing flowering was burdened with a large error. These observations indicate the need for individual calibration of estimation models in each season of assessment. This is a characteristic feature of this type of method. Calibrations should be performed (or at least tested and modified if necessary) independently for species (even cultivars) and growing seasons, to be able to estimate the desired parameters accurately (Adamsen et al. 2000; Treder et al. 2016).
The number of flowers is estimated based on the surface area of perianth petals visible in the photograph. This area depends not only on the number of flowers but also on the extent of their development, the annually changing architecture of the tree crown (density of shoots), and the extent of development of the leaves that partially cover the flowers. Detailed research conducted in 2016 showed that due to the changing surface area of perianth petals during the flowering period, calibration should be performed individually for each assessment date. Figure 7 presents two calibrations performed with the same trees three days apart, on April 22 and 25, 2016. On both dates, very high regression coefficients were obtained between the surface area of petals measured on the photographs and the number of inflorescences counted, $r^{2}=0.98$ and 0.97 , respectively. The presented linear calibration models, however, differ from each other by the values of the coefficients $a$ and $b$. In the case of the calibration performed on the first date, $1 \mathrm{~cm}^{2}$ of petals measured on the digital image corresponded to approximately 0.21 of an inflorescence, and after 5 days, when the flowers had developed more, it was 0.17 of an inflorescence. A lower absolute error of estimation was obtained on the first calibration date when the flowers were just before full bloom (Table 1). The percentage values of the MAPE, depending on the year and time of measurement, ranged from $21.8 \%$ in 2015 to $14.0 \%$ on the first assessment date in 2016.

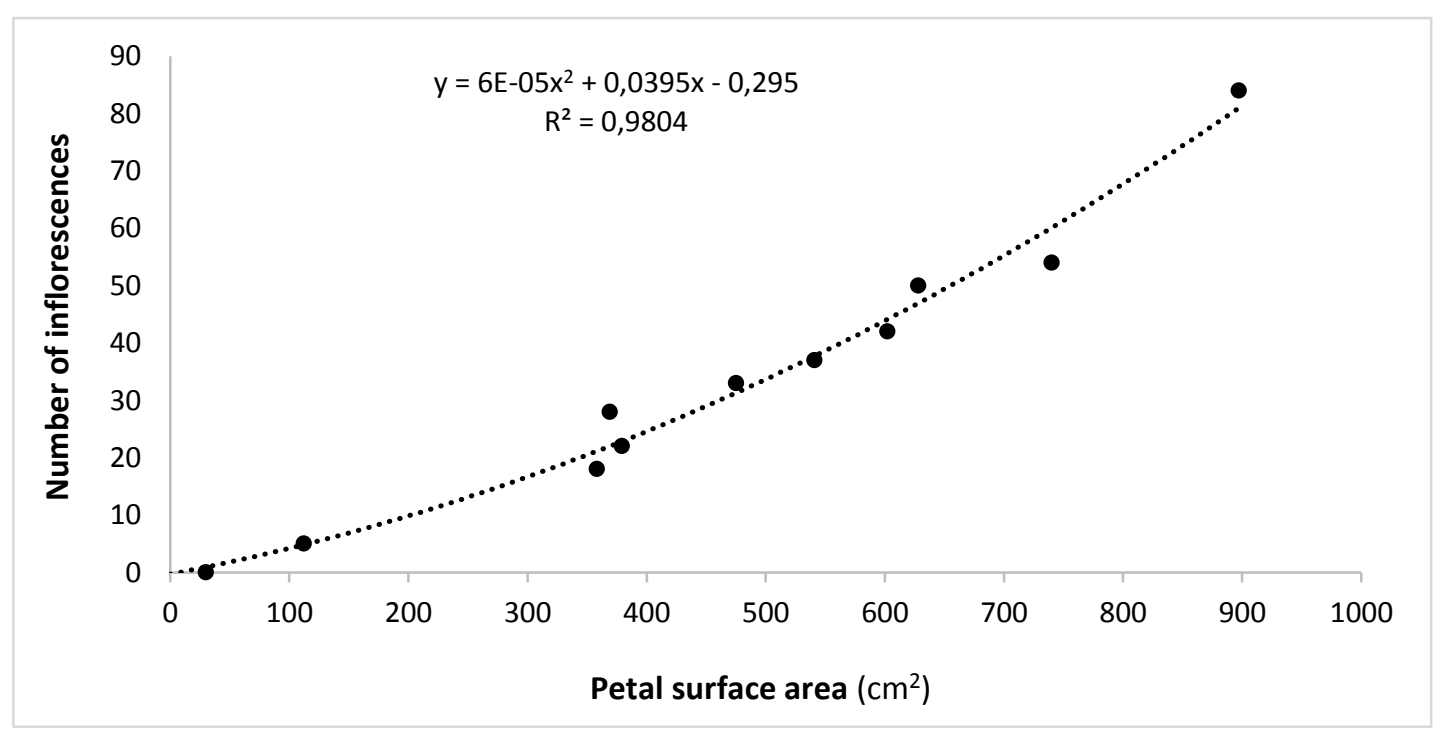

Figure 5. Calibration model for estimating the flowering of trees in $2015(n=11)$ 


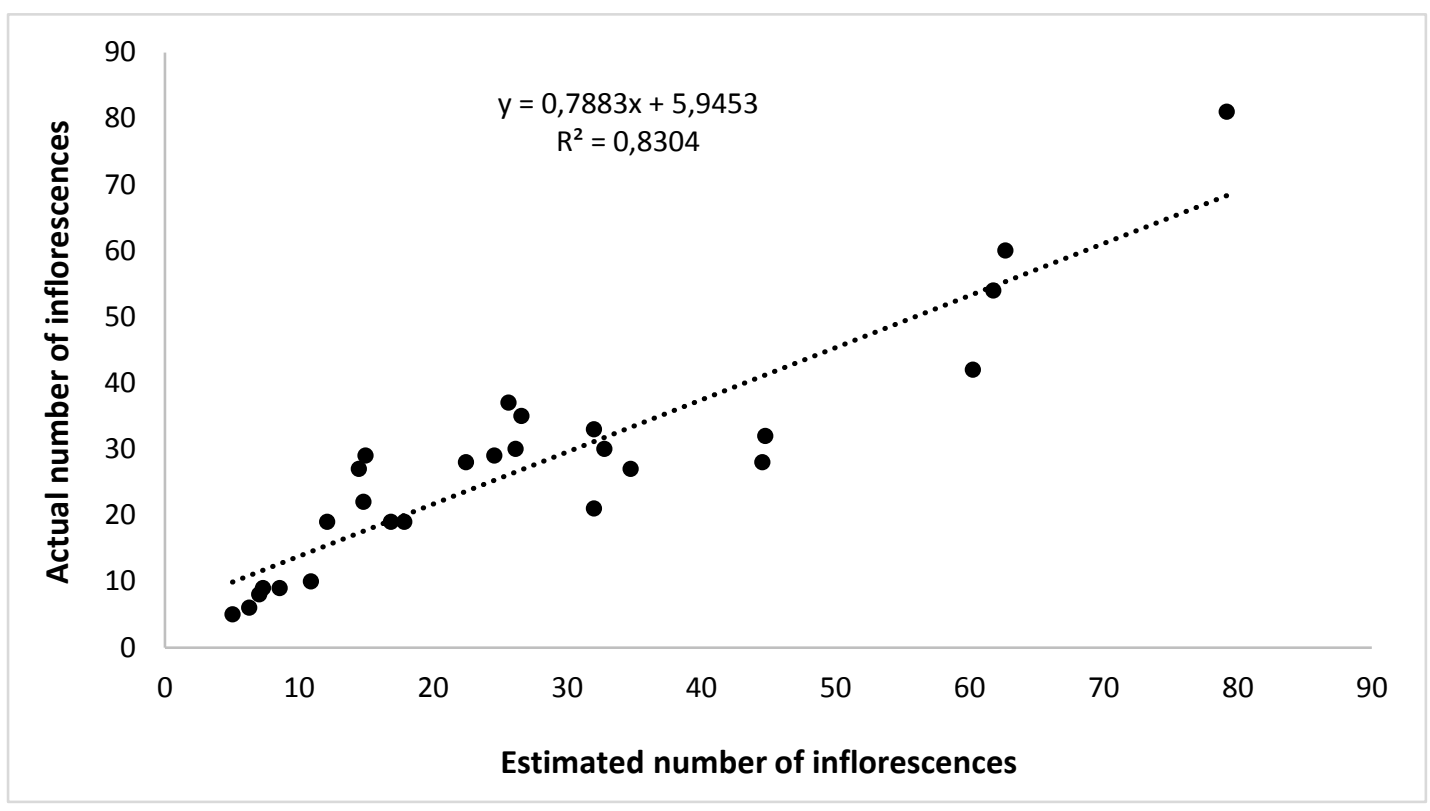

Figure 6. Correlation between the estimated number of inflorescences and the actual number of inflorescences in $2015(\mathrm{n}=27)$

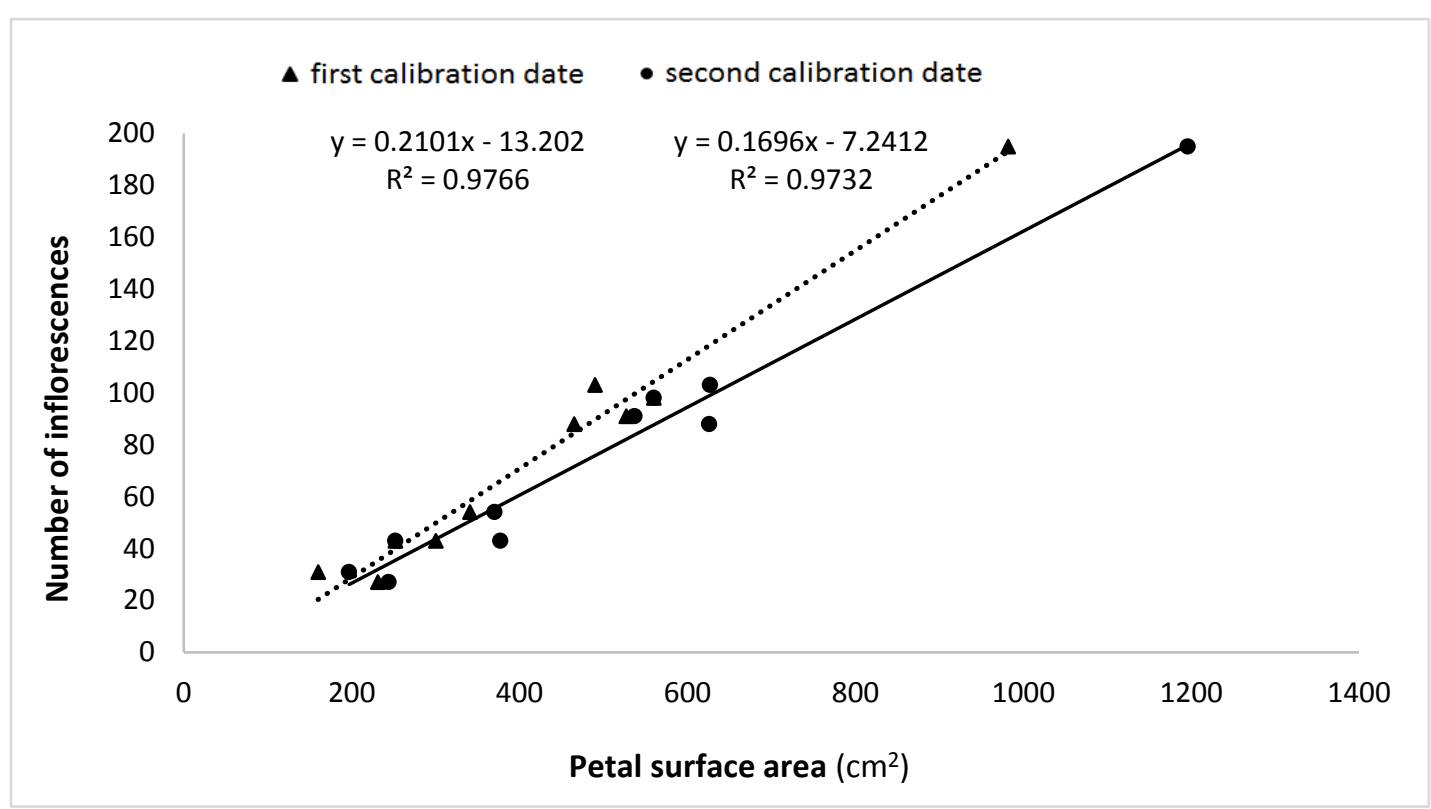

Figure 7. Calibration models for estimating the flowering of trees in $2016(\mathrm{n}=10)$

Table 1. Values of absolute error in estimating the flowering intensity of pear trees based on image analysis (2015 and 2016)

\begin{tabular}{lcc}
\hline \multicolumn{1}{c}{ Sampling date } & MAE & MAPE \\
\hline 2015 & 6.11 & $21.8 \%$ \\
\hline First measurement 2016 & 8.10 & $14.0 \%$ \\
\hline Second measurement 2016 & 11.96 & $19.1 \%$ \\
\hline
\end{tabular}


Techniques for remote detection of flowering have been demonstrated in several crops. For example, Viña et al. (2004) demonstrated the use of a spectral index (computed from several light bands) to detect the emergence of tassels in maize. Attempts to use the image processing approach for remote monitoring of flowering patterns in lesquerella canopies were made by Adamsen et al. (2000) and Thorp and Dierig (2011). Guo et al. (2015) described a method for detecting flowering panicles of paddy rice in RGB images taken under natural field conditions. According to the authors, the proposed method can quantify the daily amount and the diurnal changes of flowering, and even identify daily peaks of flowering.

Irregular flowering and fruiting is a common trait in some important horticultural plants such as apple, pear, or plum (Monselise \& Goldschmidt 1982). The annual variation in the bloom density of individual trees can cause a large variation in orchard yield (Bukovac et al. 2010). For that reason, attempts have been made to automate the process of estimating the number of flowers (clusters) in apple orchards. Aggelopoulou et al. (2011) analyzed images of blooming apple trees. An image processingbased algorithm was developed that predicted the fruit yield of an apple tree by analyzing a picture of the tree at full bloom. The algorithm showed an $18 \%$ error in the predicted yield, so optimization of it (as well as of the image-taking process) was, as stated by the authors, a necessary further step. Another at- tempt was made by Hočevar et al. (2014), who estimated the number of flower clusters of individual trees in a high-density apple orchard on the basis of image analysis with HSL (hue, saturation, and luminance) thresholding as an element of site-specific management (spraying) decisions. These results indicate that such methods have the potential to make possible intensive sampling of flowering in a variety of crop plants, and fruit yield might be predicted by analyzing flowering distribution maps.

\section{Assessment of tree growth vigor}

The assessment of tree growth vigor by means of image analysis was performed after leaf fall only in the autumn of 2015. In the autumn of 2016, the trees were so overgrown that some shoots overlapped the neighboring trees, which in the case of digital analysis prevented them from being assigned to a specific tree.

To be able to estimate the growth vigor of trees by means of image analysis of digital photographs of them, a calibration model was determined (Fig. 8). It described the correlation between the actual length of shoots measured individually for each tree and the values obtained by analyzing the photographs.

In the next step, the quality of estimating the growth vigor of pear trees using image analysis was assessed. The estimates were strongly correlated (determination coefficient of 93\%) with those determined by image analysis (Fig. 9). The MAE of estimation was $93.1 \mathrm{~cm}$, and the MAPE was $12.9 \%$.

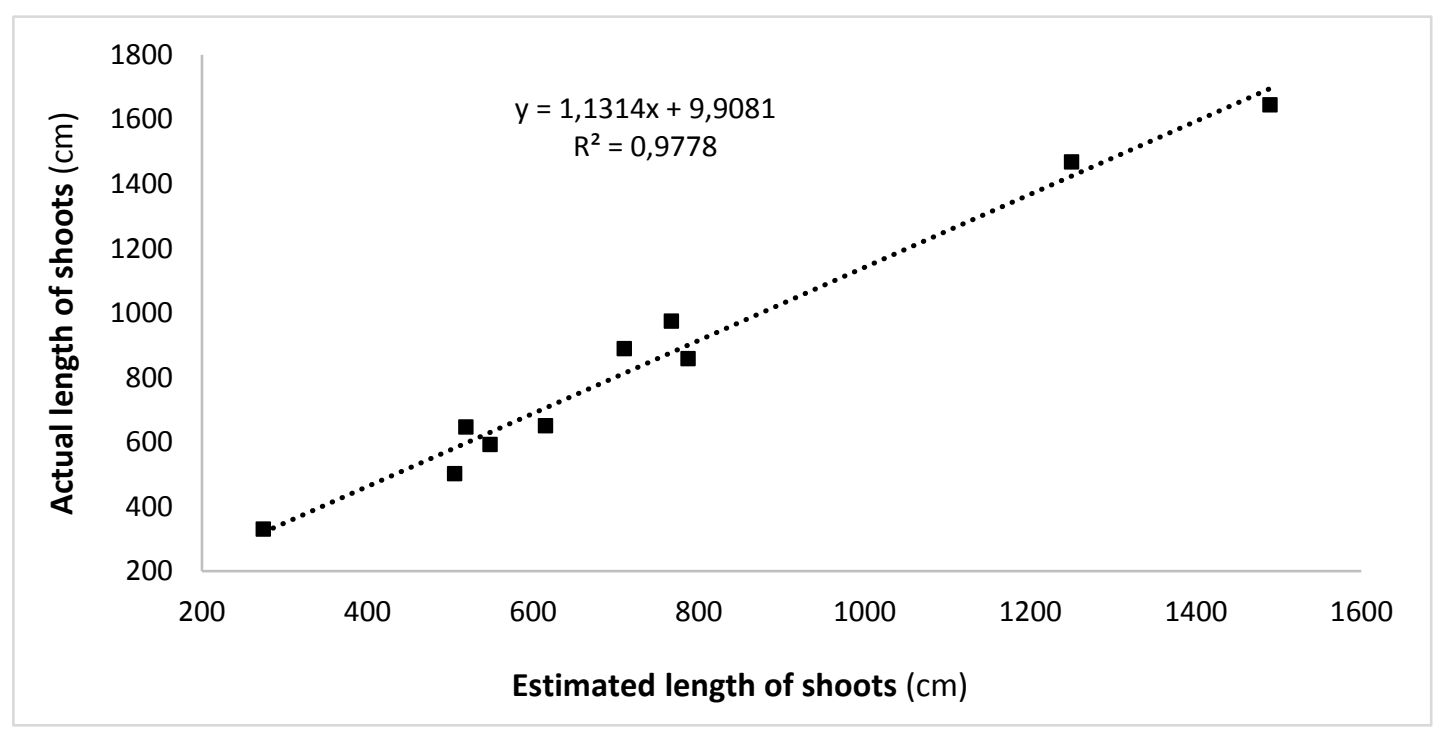

Figure 8. Calibration model for estimating tree growth vigor in $2015(\mathrm{n}=10)$ 


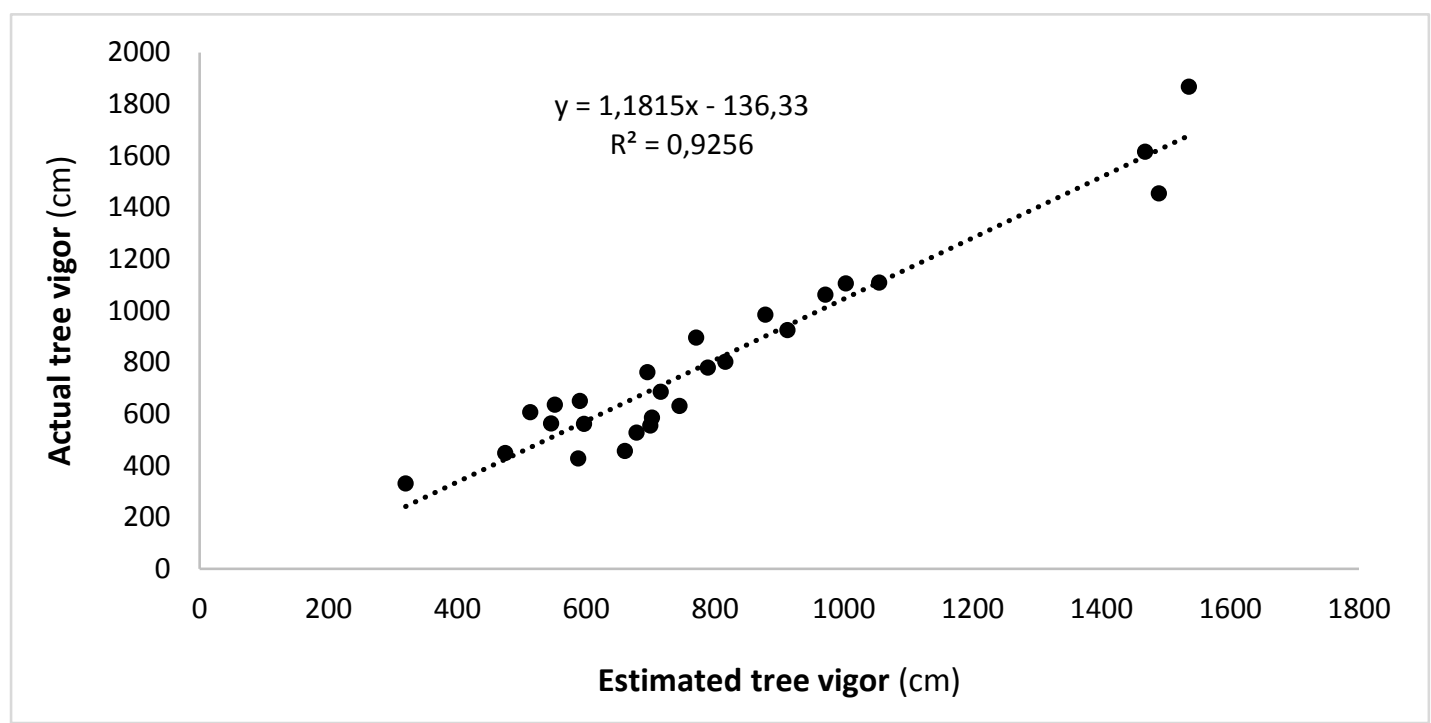

Figure 9. Correlation between the estimated tree growth vigor and the measured values $(n=26)$

In recent years, more and more attention has been paid to the measurement of plant morphological parameters using the image and video acquisition and processing systems. Much effort has been focused on nondestructive determination of leaf surface area, though there have been some attempts to use the image-processing approach to analyze plant shoot length. Polder et al. (2010) adopted the ImageJ application for measuring total shoot length from photographs of several aquatic plant species. High correlation $\left(r^{2}>91\right)$ with manual measurements proved the usefulness of the method of digital imagery and the developed analytical procedure. Brunes et al. (2016) used image processing (and the Matlab $^{\circledR}$ mathematical tool) for determining the length of shoots of wheat seedlings. The proposed method was used by the authors for separating the cultivars into different levels of vigor. Wang et al. (2011) proposed a method for modeling tea shoots with images and calculation models for nondestructive monitoring of the growth of tea shoots. A more complex system based on an image processing technique (images captured using multiple cameras) for monitoring the growth and nondestructively predicting the age and fresh weight of mustard plants was proposed by Saputra et al. (2017).

Less work has been done on fruit tree species (Lordan et al. 2015). The main reason for estimation uncertainty while using image acquisition and processing in fruit orchards is the overlapping of branches of neighboring trees (Hočevar et al. 2014) and the dependence of the applied method on illumination, which was also experienced in our study. Because the work described here was our first attempt to use digital image analysis for estimating pear tree vigor and flowering, more work is necessary to improve the image taking and processing procedure as well as to optimize the developed algorithms.

\section{CONCLUSIONS}

The methods for assessing tree flowering and growth vigor presented in the paper can in practice be used primarily for young plantings.

When assessing the intensity of flowering, photographs should be taken against a dark background during full bloom. No background is needed to assess tree growth.

In the assessment of flowering, the calibration function can be polynomial or linear. Photographs used to estimate the number of inflorescences should be taken on the same day when the calibration was performed.

To assess tree growth, the calibration function was linear. Photographs must be taken at the same distance from the trees.

\section{Acknowledgments}

This research was financially supported by the Ministry of Science and Higher Education of the Republic of Poland under statutory funds. 


\section{REFERENCES}

Abràmoff M.D., Magalhães P.J., Ram S.J. 2004. Image processing with ImageJ. Biophotonics International 11(7): 36-42.

Adamsen F.J., Coffelt T.A., Nelson J.M., Barnes E.M., Rice R.C. 2000. Method for using images from a color digital camera to estimate flower number. Crop Science 40(3): 704-709. DOI: 10.2135/cropsci2000.403704x.

Aggelopoulou A.D., Bochtis D., Fountas S., Swain K.C., Gemtos T.A., Nanos G.D. 2011. Yield prediction in apple orchards based on image processing. Precision Agriculture 12(3): 448-456. DOI: 10.1007/s11119-010-9187-0.

Arjenaki O.O., Motlagh A.M., Moghaddam P.A. 2012. A new method for estimating surface area of cylindrical fruits (zucchini) using digital image processing. Australian Journal of Crop Science 6(9): 1332-1336.

Brunes A.P., de Souza Araújo Á., Dias L.W., Villela F.A., Aumonde T.Z. 2016. Seedling length in wheat determined by image processing using mathematical tools. Revista Ciência Agronômica 47(2): 374-379. DOI: $10.5935 / 1806-6690.20160044$.

Bukovac M.J., Sabbatini P., Zucconi F., Schwallier P.G. 2010. A long-term study on native variation of flowering and fruiting in spur-type 'Delicious' apple. HortScience 45(1): 22-29. DOI: 10.21273/hortsci.45.1.22.

Byers R.E., Carbaugh D.H. 2002. Effects of thinning time on yield, fruit size, and return bloom of 'York' and 'Golden Delicious' apple trees. Journal of Tree Fruit Production 3(1): 55-62. DOI: 10.1300/J072v03n01_05.

Dobbs M., Rowling D. 2006. Revisiting the New Zealand apple industry: the impacts of change. British Food Journal 108(7): 574-585. DOI: 10.1108/00070700610676389.

Easlon H.M., Bloom A.J. 2014. Easy Leaf Area: Automated digital image analysis for rapid accurate measurement of leaf area. Applications in Plant Sciences 2(7); 1400033; 4 p. $\quad$ DOI: 10.3732/apps.1400033.

Gao J.C., Guo G.J, Guo Y.M., Wang X.X. Du Y.C. 2011. Measuring plant leaf area by scanner and ImageJ software. China Vegetables 2011(1): 73-77. [in Chinese with English abstract]

Guo W., Fukatsu T., Ninomiya S. 2015. Automated characterization of flowering dynamics in rice using fieldacquired time-series RGB images. Plant Methods 11; 7; 14 p. DOI: 10.1186/s13007-015-0047-9.
Hočevar M., Širok B., Godeša T., Stopar M. 2014. Flowering estimation in apple orchards by image analysis. Precision Agriculture 15: 466-478. DOI: 10.1007/s11119-013-9341-6.

Juneau K.J., Tarasoff C.S. 2012. Leaf area and water content changes after permanent and temporary storage. PLoS ONE 7(8); e42604; 6 p. DOI: 10.1371/journal.pone.0042604.

Lordan J., Pascual M., Fonseca F., Montilla V., Papió J., Rufat J., Villar J.M. 2015. An image-based method to study the fruit tree canopy and the pruning biomass production in a peach orchard. HortScience 50(12): 1809-1817. DOI: 10.21273/hortsci.50.12.1809.

Lukina E.V., Stone M.L., Raun W.R. 1999. Estimating vegetation coverage in wheat using digital images. Journal of Plant Nutrition 22(2): 341-350. DOI: $10.1080 / 01904169909365631$.

Monselise S.P., Goldschmidt E.E. 1982. Alternating bearing in fruit trees. Horticultural Reviews 4: 128173. DOI: 10.1002/9781118060773.ch5.

Ohnishi S., Miyoshi T., Shirai S. 2010. Low temperature stress at different flower developmental stages affects pollen development, pollination, and pod set in soybean. Environmental and Experimental Botany 69: 56-62. DOI: 10.1016/j.envexpbot.2010.02.007.

O’Neal M.E., Landis D.A., Isaacs R. 2002. An inexpensive, accurate method for measuring leaf area and defoliation through digital image analysis. Journal of Economic Entomology 95(6): 11901194. DOI: 10.1603/0022-0493-95.6.1190.

Padmavathi K., Thangadurai K. 2016. Implementation of RGB and grayscale images in plant leaves disease detection - comparative study. Indian Journal of Science and Technology 9(6); 6 p. DOI: 10.17485/ijst/2016/v9i6/77739.

Patil S.B., Bodhe S.K. 2011. Image processing method to measure sugarcane leaf area. International Journal of Engineering Science and Technology 3(8): 6393-6400.

Polder G., Hovens H.L.E., Zweers A.J. 2010. Measuring shoot length of submerged aquatic plants using graph analysis. Proceedings of the ImageJ User and Developer Conference 2010, Mondorf-les-Bains, Luxembourg, October 27-29, pp. 172-177.

Reginato G.M. 2002. Theoretical quantitative approximation of density of plantations and determination of behavior of apple orchards. Revista Frutícola 23(3): 93-96.

Rueden C.T., Schindelin J., Hiner M.C., DeZonia B.E., Walter A.E., Arena E.T., Eliceiri K.W. 2017. ImageJ2: ImageJ for the next generation of scientific image data. BMC Bioinformatics 18(1); 529; 26 p. DOI: 10.1186/s12859-017-1934-z. 
Saputra T.W., Masithoh R.E., Achmad B. 2017. Development of plant growth monitoring system using image processing techniques based on multiple images. Proceeding of the 1st International Conference on Tropical Agriculture, Bulaksumur, Indonesia, pp. 647-653. DOI: 10.1007/978-3-319-60363-6_65.

Schindelin J., Arganda-Carreras I., Frise E., Kaynig V., Longair M., Pietzsch T. et al. 2012. Fiji: an opensource platform for biological-image analysis. Nature Methods 9(7): 676-682. DOI: 10.1038/nmeth.2019.

Schneider C.A., Rasband W.S., Eliceiri K.W. 2012. NIH Image to ImageJ: 25 years of image analysis. Nature Methods 9(7): 671-675. DOI: 10.1038/nmeth.2089.

Spalding E.P., Miller N.D. 2013. Image analysis is driving a renaissance in growth measurement. Current Opinion in Plant Biology 16: 100-104. DOI: 10.1016/j.pbi.2013.01.001.

Theron K.I., Steyn W.J., Jacobs G. 2000. Induction of proleptic shoot formation on pome fruit nursery trees. Acta Horticulturae 514: 235-244. DOI: 10.17660/actahortic.2000.514.27.
Thorp K.R., Dierig D.A. 2011. Color image segmentation approach to monitor flowering in lesquerella. Industrial Crops and Products 34(1): 1150-1159. DOI: 10.1016/j.indcrop.2011.04.002.

Treder W. 2010. Crop loading studies with 'Jonagold' apple tree. Journal of Fruit and Ornamental Plant Research 18(1): 59-69.

Treder W., Klamkowski K., Kowalczyk W., Sas D., Wójcik K. 2016. Possibilities of using image analysis to estimate the nitrogen nutrition status of apple trees. Zemdirbyste-Agriculture 103(3): 319326. DOI: 10.13080/z-a.2016.103.041.

Viña A., Gitelson A.A., Rundquist D.C., Keydan G.P., Leavitt B., Schepers J.S. 2004. Monitoring maize (Zea mays L.) phenology with remote sensing. Agronomy Journal 96(4): 1139-1147. DOI: 10.2134/agronj2004.1139.

Wang J., Zeng X., Liu J. 2011. Three-dimensional modeling of tea-shoots using images and models. Sensors 11(4): 3803-3815. DOI: 10.3390/s110403803. 